\title{
Extended therapeutic window for caspase inhibition and synergy with MK-801 in the treatment of cerebral histotoxic hypoxia
}

\author{
Jörg B. Schulz ${ }^{1,5}$, Michael Weller ${ }^{1}$, Russell T. Matthews ${ }^{1,2}$, \\ Michael T. Heneka ${ }^{1}$, Peter Groscurth ${ }^{3}$, \\ Jean-Claude Martinou ${ }^{4}$, Jürgen Lommatzsch ${ }^{1}$, \\ Rainer von Coelln ${ }^{1}$, Ullrich Wüllner ${ }^{1}$, Peter-A. Löschmann ${ }^{1}$, \\ M. Flint Beal ${ }^{2}$, Johannes Dichgans ${ }^{1}$ and \\ Thomas Klockgether ${ }^{1}$
1 Experimental Neuropharmacology Laboratory, Department of Neurology, University of Tübingen, Hoppe-Seyler-Str. 3, D-72076 Tübingen, Germany
2 Neurochemistry Laboratory, Neurology Service, Massachusetts General Hospital and Harvard Medical School, 32 Fruit St., Boston, MA 02114, USA
${ }^{3}$ Institute of Anatomy, Division of Cell Biology, University of Zürich, Winterthurerstr. 190, Ch-8057 Zürich, Switzerland
${ }^{4}$ Glaxo Institute for Molecular Biology, Neurology Research, 14 chemin des Aulx, 1228 Plans-les-Ouates, Geneve, Switzerland
${ }^{5}$ corresponding author: Jörg B. Schulz, Department of Neurology, University of Tübingen, Hoppe-Seyler-Str. 3, D-72076 Tübingen, Germany, Tel: **49-7071-2982141, Fax: ${ }^{* *} 49-7071-296507$, e-mail: joerg.b.schulz@uni-tuebingen.de

Received 31.03.98; revised 05.05.98; accepted 18.05.98 Edited by G. Melino

\begin{abstract}
In rats, striatal histotoxic hypoxic lesions produced by the mitochondrial toxin malonate resemble those of focal cerebral ischemia. Intrastriatal injections of malonate induced cleavage of caspase-2 beginning at $6 h$, and caspase-3-like activity as identified by DEVD biotin affinity-labeling within $12 \mathrm{~h}$. DEVD affinity-labeling was prevented and lesion volume reduced in transgenic mice overexpressing BCL-2 in neuronal cells. Intrastriatal injection of the tripeptide, N-benzyloxycarbonylVal-Ala-Asp-fluoromethylketone (zVAD-fmk), a caspase inhibitor, at $3 \mathrm{~h}, 6 \mathrm{~h}$, or $9 \mathrm{~h}$ after malonate injections reduced the lesion volume produced by malonate. A combination of pretreatment with the NMDA antagonist, dizocilpine (MK-801), and delayed treatment with ZVAD-fmk provided synergistic protection compared with either treatmentalone and extended the therapeutic window for caspase inhibition to $12 \mathrm{~h}$. Treatment with cycloheximide and ZVAD-fmk, but not with MK-801, blocked the malonate-induced cleavage of caspase2. NMDA injections alone resulted in a weak caspase-2 cleavage. These results suggest that malonate toxicity induces neuronal death by more than one pathway. They strongly implicate early excitotoxicity and delayed caspase activation in neuronal loss after focal ischemic lesions and offer a new strategy for the treatment of stroke.
\end{abstract}

Keywords: Caspases; malonate; apoptosis; excitotoxicity; therapeutic window; Nedd2
Abbreviations: DMSO, dimethyl-sulfoxide; MK-801, dizocilpine; NMDA, N-methyl-D-aspartate; PFA, paraformaldehyde; TTC, 2,3,5-triphenyl-tetrazolium chloride monohydrate; TUNEL, terminal transferase dUTP nick end-labeling; zVAD-fmk, N-benzyloxycarbonyl-Val-Ala-Asp-fluoromethylketone

\section{Introduction}

Excitotoxic and apoptotic cell death may contribute to neuronal loss in human neurodegenerative diseases and cerebral ischemia. Depending on the severity of the insult, excitotoxic cell death may be either necrotic or apoptotic (Ankarcrona et al, 1995; Bonfoco et al, 1995). Evidence that ischemic cell death involves apoptosis comes from in situ DNA end-labeling (TUNEL) and laddering on DNA gel electrophoresis in global and focal experimental ischemia (Choi, 1996). Ultrastructural morphological evidence for apoptosis in ischemic neuronal tissue is limited ( $\mathrm{Li}$ et al, 1995b) or lacking (Campagne and Gill, 1996).

Studies in Caenorhabditis elegans have led to the identification of three cell death genes, ced-3, ced-4, and ced-9. Mammalian homologs of ced-9 and ced-3 genes include proteins of the BCL-2 and caspase (formerly called ICE-like protease) families (Alnemri et al, 1996). A dominant role for caspase-3 in neuronal apoptosis has been suggested in studies using transgenic animals. The nervous system of caspase-1-deficient mice develops normally ( $\mathrm{Li}$ et al, 1995a), but caspase-3-deficient mice show decreased apoptosis primarily in neurons (Kuida et al, 1996). Yet, most human central nervous system neurons exhibit little or no caspase-3 immunoreactivity except in ischemic degeneration (Krajewska et al, 1997). Overexpression of BCL-2 in neurons (Martinou et al, 1994) protects against ischemia. Repeated intracerebroventricular administration of an irreversible caspase inhibitor, Nbenzyloxycarbonyl-Val-Ala-Asp-fluoromethylketone (zVADfmk) (Hara et al, 1997), or transgenic expression of a mutant caspase-1 inhibitory protein, reduces damage in focal cerebral ischemia (Friedlander et al, 1997).

Malonate is a reversible succinate dehydrogenase inhibitor which produces secondary excitotoxic lesions similar to those of focal ischemia when administered intrastriatally. As in the penumbral region of focal ischemic lesions, malonate lesions are associated with metabolic compromise, sparing of NADPH diaphorase-positive neurons and somatostatin concentrations, and are attenuated by NMDA antagonists, glutamate release inhibitors, free radical scavengers, and inhibitors of neuronal nitric oxide synthase (Beal et al, 1993; Greene et al, 1993; Henshaw et al, 1994; Schulz et al, 1995a,b). In the present study, we show that delayed treatment with the caspase inhibitor 
zVAD-fmk or overexpression of BCL-2 protects against malonate-induced lesions. We present a new therapeutic strategy for the treatment of stroke that is based on the synergistic combination of zVAD-fmk and MK-801.

\section{Results}

\section{Malonate-induced neuronal cell death: insignificant role of apoptosis but attenuation by BCL-2}

The first series of experiments was designed to characterize the type of neuronal cell death induced by malonate. Brain sections were stained to detect TUNEL-positive cells at $24 \mathrm{~h}$ after striatal injection of $3 \mu \mathrm{mol}$ malonate in rats. A limited number of TUNEL-positive cells with signs of chromatin condensation or fragmentation were detected in the transition zone but not in the core of the lesion. These accounted for only $2 \%$ of cells in the striatum. (Figure $1 \mathrm{~A}$ ). When the same brain areas were analyzed by electron microscopy, we observed numerous neurons with an increased density of cytoplasm, damaged membranes, swollen organelles and irregularly shaped nuclei with only slightly condensed heterochromatin and intact nucleolus (Figure $1 \mathrm{~B}$ and $\mathrm{C}$ ). Ultrastructural examination therefore did not show typical morphological features of apoptosis. Next, we asked whether overexpression of BCL-2 protected against striatal lesions produced by malonate. The lesion volume induced by striatal injection of $750 \mathrm{nmol}$ malonate was significantly reduced in bcl-2 transgenic mice as compared with the lesion volume in littermates when measured at 7 days (Figure 2). Thus, malonate-induced neurotoxicity is a non-apoptotic type of cell death that is inhibited by the classical antiapoptotic gene product, BCL-2.

\section{Bcl-2-sensitive activation of caspases by malonate}

Prevention of apoptosis by bcl-2 involves, amongst others, inhibition of activation of caspases (Armstrong et al, 1996; Schulz et al, 1997). Therefore, we looked for evidence of caspase activation in malonate-lesioned brain tissue. Caspase activation requires partial proteolytic cleavage of full length procaspases $(32-51 \mathrm{kDa})$ into active subunits. Caspase-1 (ICE) rather specifically cleaves YVAD whereas caspase-3-like proteases cleave DEVD. Labeling of striatal extracts with biotinylated DEVD-CHO revealed the induction of a $20 \mathrm{kDa}$ fragment (p20) at 12 and $24 \mathrm{~h}$, but not at earlier time points, after striatal malonate injections in rats (Figure $3 \mathrm{~A}$, upper panel). p20 was not detected in the contralateral hemisphere that received saline control injections. The fragment corresponds to the larger subunit of an activated caspase family member. No time-dependent increase in labeling was observed with biotinylated YVAD-CHO at the same time points in rats (Figure $3 \mathrm{~A}$, lower panel). Therefore, our results suggest that caspase-3-like proteases but not caspase-1, are activated in the process of malonate toxicity. At $24 \mathrm{~h}$ after malonate injection, a p20 fragment labeled with biotinylated DEVD-CHO was also detected in the striatum of mice (Figure $3 \mathrm{~B}$ ). This fragment was not detected in littermates engineered to express high levels of BCL-2 in neurons, suggesting that BCL-2 acts upstream from caspases in vivo.

\section{Malonate induces caspase-2 activation}

To identify the specific caspase which is cleaved after striatal malonate injections we used several antibodies (see Materials and Methods) against caspase-1, -2 , and -3 . Although all antibodies used recognized the respective procaspase (data not shown), only the Nedd-2 antibody directed against the $\mathrm{N}$-terminus of Nedd-2 recognized a cleaved fragment of $\sim 24 \mathrm{kDa}$ (Figure 4A). This fragment first appeared with a weak signal at $6 \mathrm{~h}$, and with a stronger signal at 9, 12, and $24 \mathrm{~h}$. This fragment was also detected at $24 \mathrm{~h}$ after malonate lesions in wild-type mice. Cleavage was not detected in bcl-2 transgenic littermates (data not shown). Further, intraperitoneal treatment of animals with cycloheximide $(10 \mathrm{mg} / \mathrm{kg})$ at the timepoint of striatal malonate injection, or striatal co-injection of zVAD-fmk blocked the activation of the $\sim 24 \mathrm{kDa}$ fragment. No such effects were seen after striatal co-injection of DEVD-CHO or systemic treatment with MK-801 $(5 \mathrm{mg} / \mathrm{kg}$ ) at the time of striatal malonate injections (Figure 4B). Compared with malonate, striatal injection of $300 \mathrm{nmol}$ NMDA which induce a comparable lesion size (Schulz et al, $1995 \mathrm{a})$, only induced a weak signal of the activated $24 \mathrm{kDa}$ fragment at $12 \mathrm{~h}$ (Figure 4C).

\section{Time course of malonate histopathology}

Next, we studied the temporal profile of malonate histopathology to correlate the development of malonate-induced neuronal death with the time course of caspase activation. There was a gradual increase of the lesion volume from 3$24 \mathrm{~h}$ (Figure 5 and 6). At 6, 9 and $12 \mathrm{~h}$ the brain region involved could be separated into two different areas. The core of the lesion presented as infarction (a region of parenchymal pan-necrosis due to death of astrocytes as well as neurons). At 6,9 and $12 \mathrm{~h}$ a transition zone was apparent next to the infarcted area in which some neurons appeared morphologically affected as red neurons but were still viable. In this zone, there also was a certain degree of myelin pallor. At 12 and $24 \mathrm{~h}$ after malonate injection, this transition zone was found to be included in the demarcated lesion area. At 7 days there was a massive glial response with proliferation of GFAPpositive astrocytes (not shown) and microglia. Thus, the onset of caspase activation coincides with the development of a transition zone and precedes the development of the final infarction zone.

\section{zVAD-fmk and MK-801 attenuate malonate-induced striatal lesions}

Next, we sought to clarify whether the activation of caspases played a role in malonate-induced lesion formation. We examined whether pharmacological inhibitors of caspases reduced malonate-induced lesion volumes. Intrastriatal injection of $200 \mu \mathrm{g}$ zVAD-fmk ( 400 $\mu \mathrm{mol}$ dissolved in $2 \mu \mathrm{l}$ DMSO) $1 \mathrm{~h}$ before intrastriatal injection of malonate, via chronically implanted guide cannulas, significantly attenuated the lesion volume as compared with DMSO-treated controls 
(Figure 7A). Intrastriatal control injections of $2 \mu \mathrm{l}$ DMSO alone did not cause any damage (data not shown). Pretreatment with zVAD-fmk also decreased the number of TUNEL-positive neurons at $24 \mathrm{~h}$ after malonate injection (Figure 7B). The slightly larger lesion volume produced by $3 \mu \mathrm{mol}$ malonate in vehicle-pretreated animals in this study, as compared with earlier reports (Henshaw et al, 1994; Schulz et al, 1995a,b,c), is most likely due to the increased penetrance of malonate into neurons after pretreatment with DMSO. In subsequent experiments (Figure 8 and 9), only $1 \mu \mathrm{g}$ zVAD-fmk dissolved in $2 \mu \mathrm{l}$ of $1 \%$ DMSO was injected into the striatum which was as effective as the higher dose.

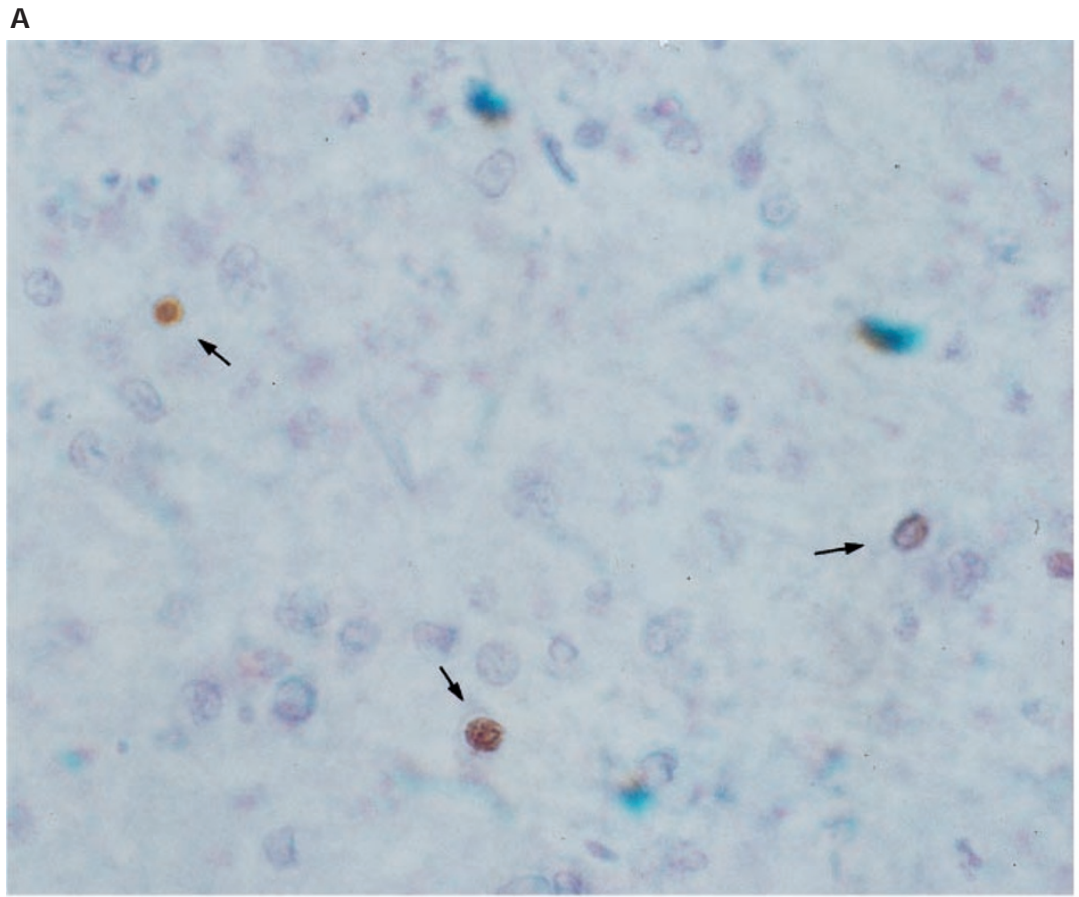

B

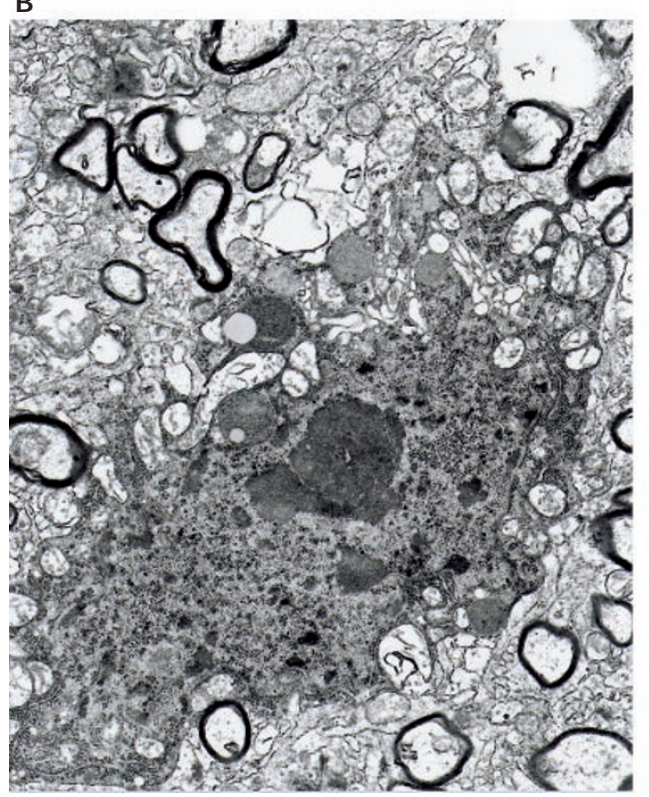

C

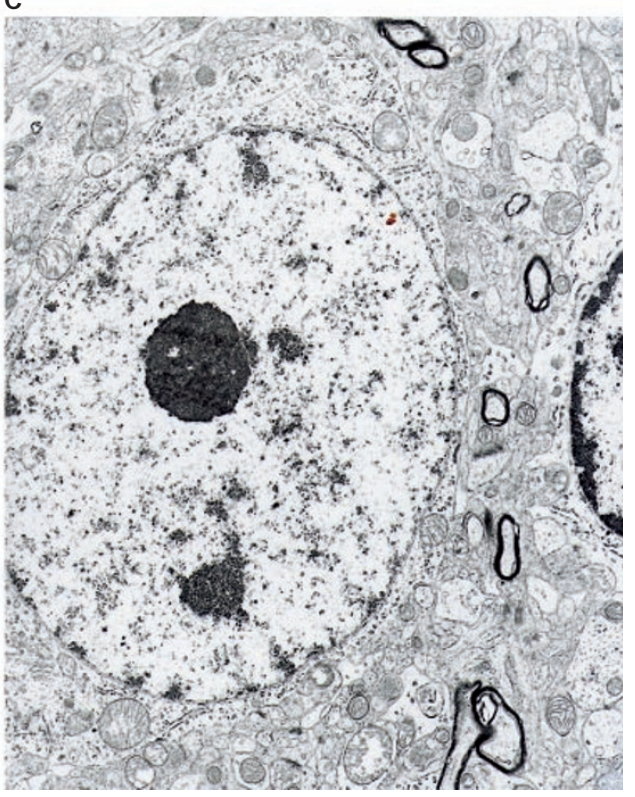

Figure 1 Morphology of cell death induced by malonate. (A) Intrastriatal malonate injections induce DNA breaks in a minority of neurons. Rat brain striatal sections were studied by in situ DNA end labeling at $24 \mathrm{~h}$ after malonate-induced striatal lesions. In the transition zone, only few cells are labeled and show margination, condensation and fragmentation of chromatin (arrows). (B) Electron microscopy in the transition zone of malonate-induced striatal lesions at $24 \mathrm{~h}$ shows numerous cells with increased density of cytoplasm, damaged membranes, swollen organelles and irregularly shaped nucleus with only slightly condensed heterochromatin and intact nucleolus, compared with $(\mathbf{C})$ the contralateral, unaffected striatum 
Since the activation of caspases was not detectable earlier than $6 \mathrm{~h}$ after striatal malonate injection, we examined whether delayed treatment with zVAD-fmk also

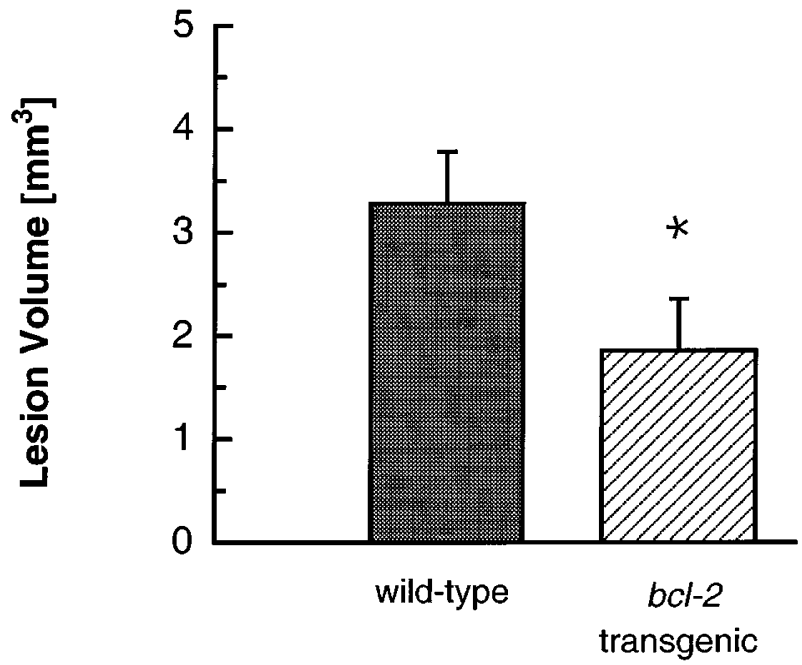

Figure $2 \mathrm{Bcl}-2$-transgenic mice are protected from malonate neurotoxicity Transgenic BCL-2 overexpressing mice were injected with $0.75 \mu \mathrm{mol}$ of malonate and lesion volumes assessed by cresyl violet staining at 7 days (mean \pm S.E.M., $n=12,{ }^{*} P<0.05$ )

A

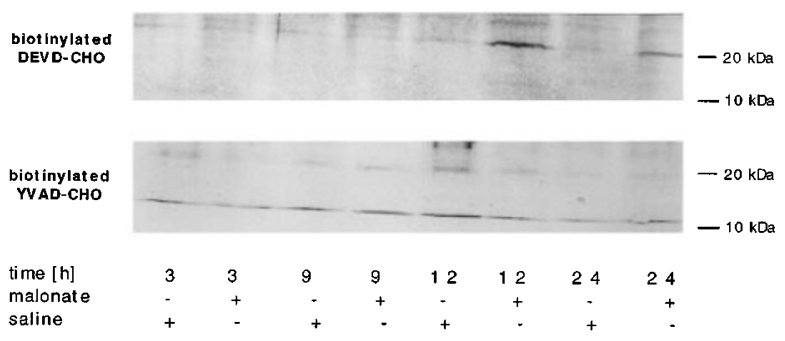

B

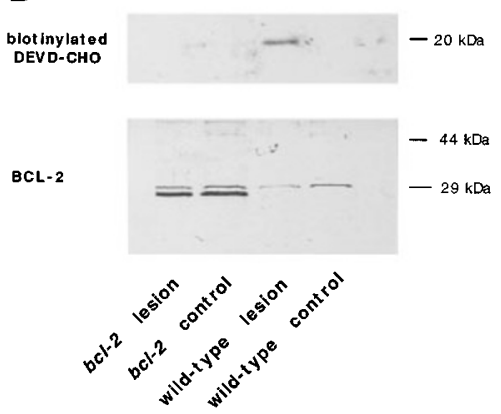

Figure 3 Activation of BCL-2-sensitive caspases in striatal malonate lesions. (A) Time course of $\sim$ p20 induction as detected by immunoblot analysis of striatal extracts labeled with biotinylated DEVD-CHO. There is no induction of a subunit labeled with biotinylated YVAD-CHO. (B) The induction of a $\sim$ p20 fragment is blocked (top) in mice with forced neuronal expression of $\mathrm{BCL}-2$ (bottom). p20 was detected as in (A), upper panel. BCL-2 protein was detected by immunoblot analysis. Note that the transgene-derived BCL-2 protein migrates somewhat faster than the endogenous BCL-2 protein provided protection. We previously showed that the glutamate release inhibitor, lamotrigine, and the NMDA antagonist, MK-801, exert neuroprotective effects against malonate toxicity when administered within 1 and $2 \mathrm{~h}$, respectively (Schulz et al, 1995b). Treatment with $1 \mu \mathrm{g}$ zVAD-fmk attenuated the lesion volume produced by malonate when injected at 3,6 and $9 \mathrm{~h}$ but not at $12 \mathrm{~h}$ after malonate injections (Figure $8 \mathrm{~A}$ ). Interestingly, treatment at $3 \mathrm{~h}$ was not superior to treatment at $9 \mathrm{~h}$. Treatment with $5 \mathrm{mg} / \mathrm{kg} \mathrm{MK-801} \mathrm{i.p.} 1 \mathrm{~h}$ before malonate injection was similarly effective, whereas treatment with MK-801 at $3 \mathrm{~h}$ after malonate injection was not protective (Figure $8 \mathrm{~B}$ ). The combination of pretreatment with MK-801 and posttreatment with zVAD-fmk at 3, 6 and $12 \mathrm{~h}$ was superior to either treatment alone (Figure 9). In the presence of MK-801, posttreatment with ZVAD-fmk was still effective at $12 \mathrm{~h}$. Moreover, following MK-801 pretreatment, zVAD-fmk administration at $12 \mathrm{~h}$ was almost as effective in terms of neuroprotection as administration at $3 \mathrm{~h}$. According to the

A
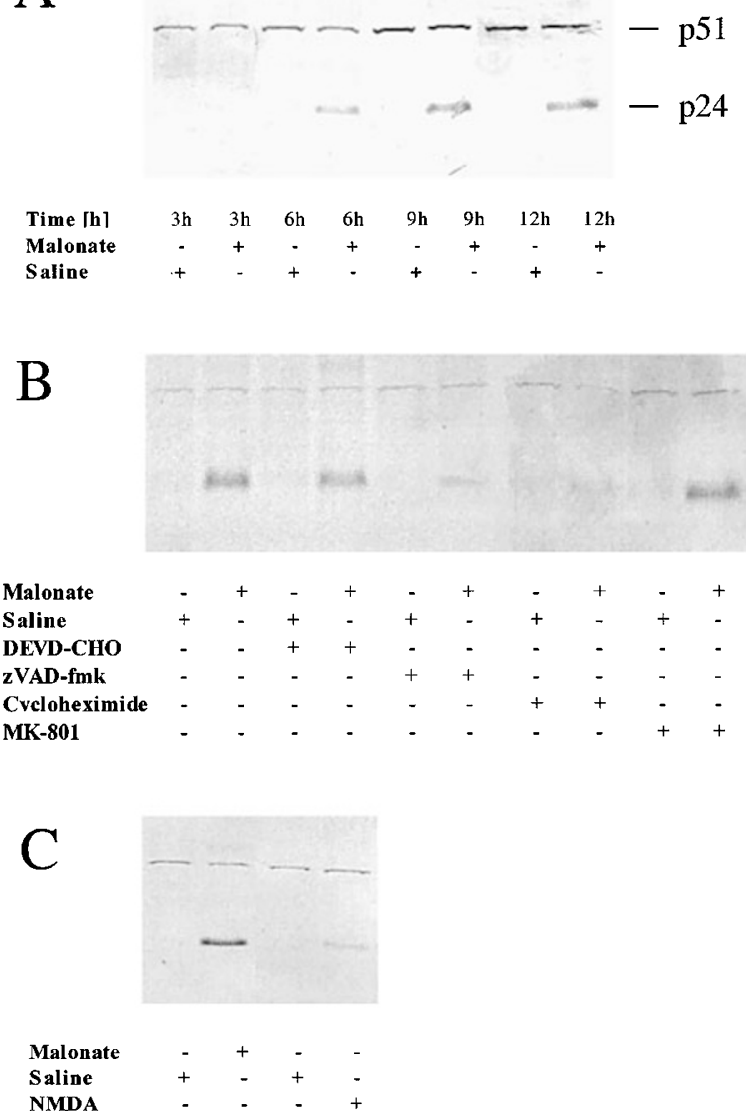

Figure 4 Malonate-induced cleavage of caspase-2 (NEDD2). (A) Time course of $\sim$ p24 cleavage as detected by immunoblot analysis of striatal extracts using an anti caspase-2 N-terminal specific antibody. (B) Effects on malonate-induced caspase-2 cleavage by intraperitoneal treatment with cycloheximide $(10 \mathrm{mg} / \mathrm{kg})$ or MK-801 $(5 \mathrm{mg} / \mathrm{kg})$, or striatal co-administration of zVAD-fmk or DEVD-CHO. (C) At $12 \mathrm{~h}$ after striatal injection, NMDA leads only to a weak signal of caspase-2 cleavage 
fractional product method (see Methods), the observed effect moderately exceeded the predicted independent effects of combination therapy, suggesting that these treatments act in an additive manner to provide neuroprotection, or even in synergy.
Putative synergistic effects of drugs can be studied best when subthreshold dosages of these therapeutics are combined, which itself have no or only a weak beneficial effect (Greco et al, 1995). Therefore, we first studied the dose response curves for systemic treatment of MK-801
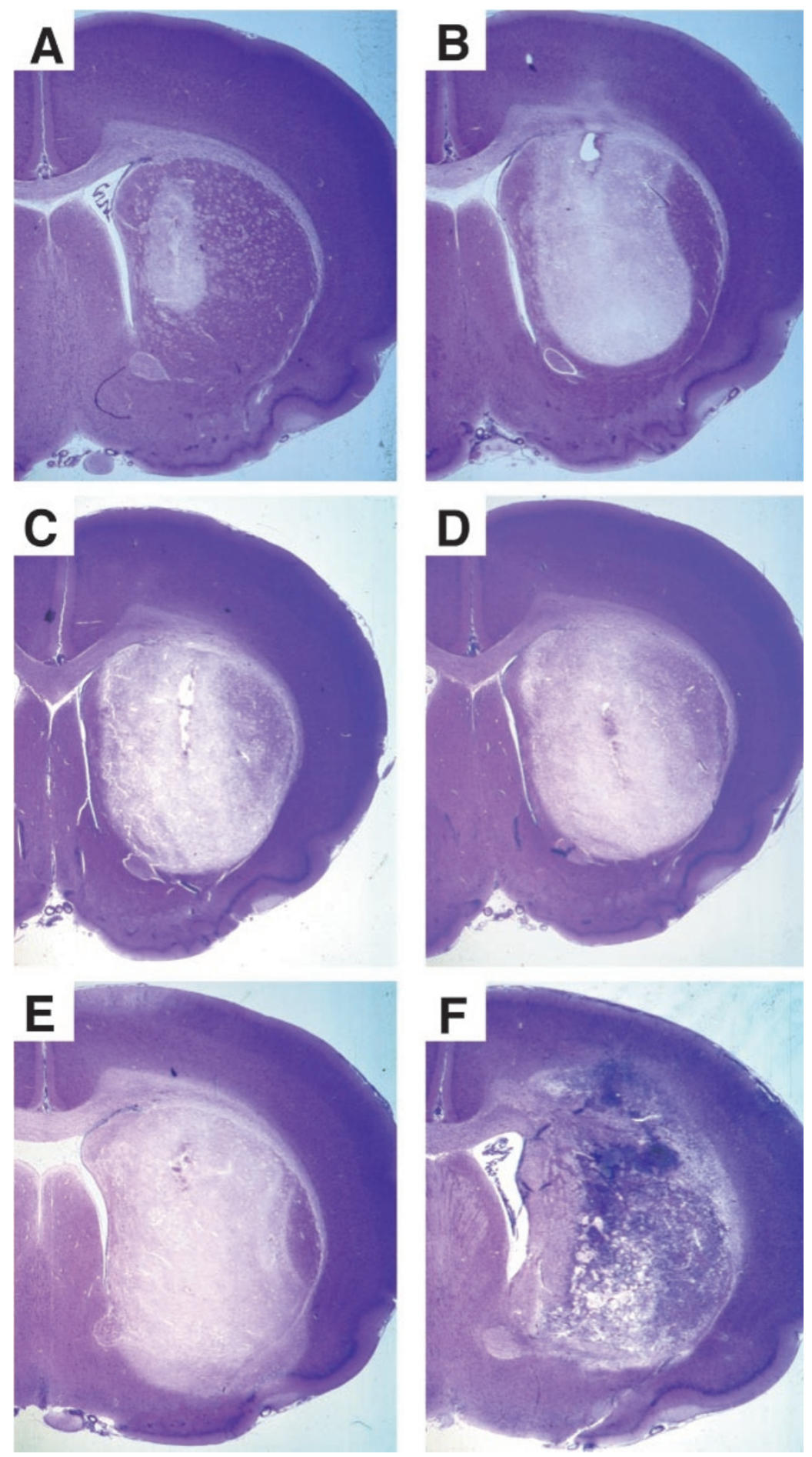

Figure 5 Time course of malonate histopathology. Representative micrographs show cresyl-violet stained sections of the striatum at $3 \mathrm{~h}(\mathbf{A}), 6 \mathrm{~h}(\mathbf{B}), 9 \mathrm{~h}(\mathbf{C}), 12 \mathrm{~h}$ (D), $24 \mathrm{~h}(\mathbf{E})$ and 7 days (F) after striatal injections of $3 \mu \mathrm{mol}$ malonate. The core of the lesion presented as infarction and was surrounded by a transition zone. In the transition zone, there was a certain degree of myelin pallor and some neurons appeared morphologically affected but most neurons were still viable 


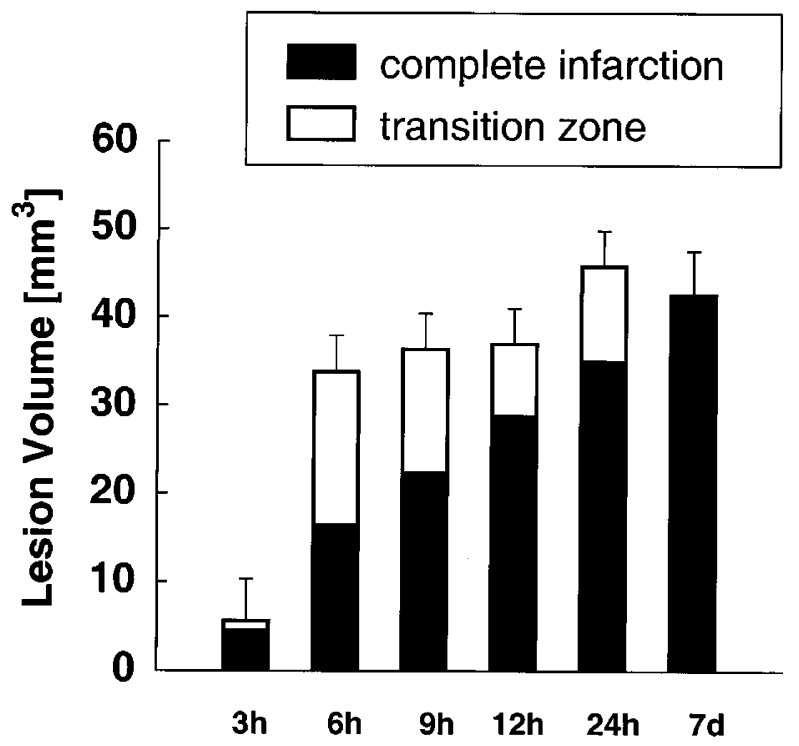

Figure 6 Temporal profile of malonate-induced lesion volumes. The lesion volumes were separated into an area of complete infarction and a transition zone (mean \pm S.E.M., $n=4)$

administered i.p. $0.5 \mathrm{~h}$ before striatal malonate injections (Figure 10A) and for intrastriatal injection of zVAD-fmk at $3 \mathrm{~h}$ after malonate treatment (Figure 10B). Both drugs provided dose-dependent protection. A combination of treatment with $0.5 \mathrm{mg} / \mathrm{kg}$ MK-801 i.p. at $0.5 \mathrm{~h}$ before malonate injections and $20 \mathrm{ng}$ ZVAD-fmk at $3 \mathrm{~h}$ provided strong synergistic effects as calculated by the fractional product method (Figure 10C). At these concentrations, both drugs on its own provide only marginal effects. This protection was as good as the effects observed after combination of $0.5 \mathrm{mg} / \mathrm{kg}$ MK-801 with $1000 \mathrm{ng}$ zVAD-fmk. At these concentrations MK-801 did not cause hypothermia in the free moving, non-anesthetized animals.

\section{Discussion}

The hypothesis that ischemia-induced neuronal cell death involves apoptosis and is genetically regulated raises the possibility of specific interventions that could act in synergy with anti-excitotoxic therapies and allow for a prolonged therapeutic window (Choi, 1996). Here, we report that malonate induces an active type of cell death depending on cycloheximide-sensitive activation of caspases. Inhibition of caspase activation by BCL-2 expression or pharmacological agents heralds new therapeutic approaches that are shown here to protect neurons in synergy with anti-excitotoxic treatment. Our results confirm earlier reports of protection in focal ischemia by pharmacological caspase inhibition (Hara et al, 1997) or expression of a dominant negative mutant of caspase-1 in transgenic mice (Friedlander et al, 1997).

There was no major role of apoptosis in malonateinduced histochemical hypoxia. In the transition zone, only $2 \%$ of cells were TUNEL-positive and showed features of
A

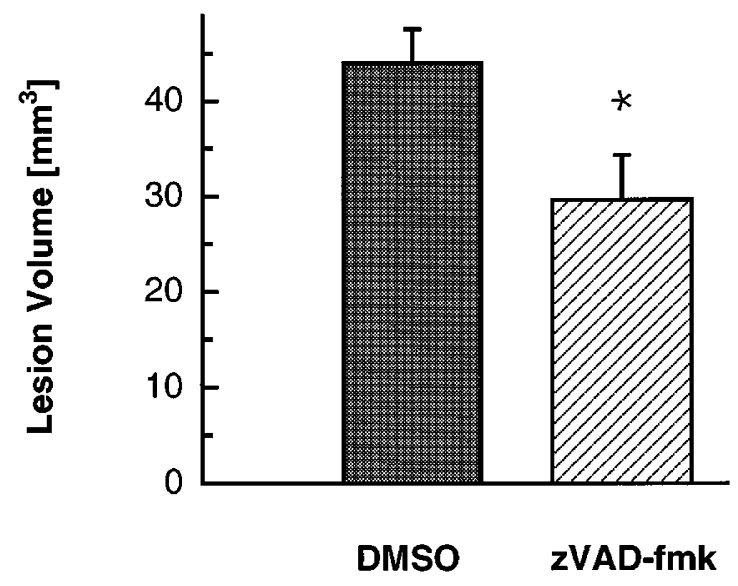

B

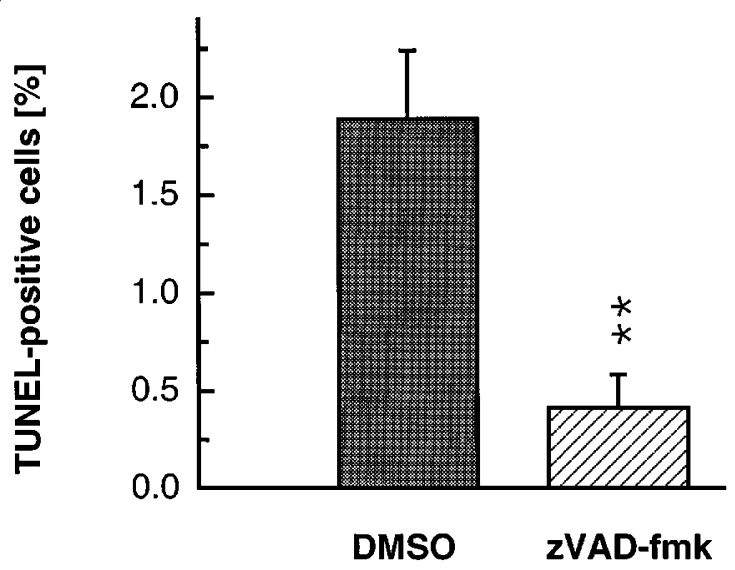

Figure 7 zVAD-fmk attenuates striatal lesions produced by malonate. $200 \mu \mathrm{g}$ zVAD-fmk dissolved in $2 \mu \mathrm{I}$ DMSO or $2 \mu \mathrm{l}$ DMSO alone (vehicle-treated control) were injected into the striatum $30 \mathrm{~min}$ before striatal malonate injections. (A) Analysis of lesion volume 7 days after striatal malonate injections. (B) Analysis of TUNEL-positive neurons expressed as percentage of striatal neurons (mean \pm S.E.M., $n=3,{ }^{*} P<0.05,{ }^{* *} P<0.01$ )

apoptosis. Since the number of TUNEL-positive cells was small, we may have missed neurons with ultrastructural features of apoptosis in the electron microscopic studies. Yet, interfering with a genetic pathway typical of apoptosis, by means of overexpression of BCL-2 or pharmacological inhibition of caspases, protected from malonate-induced histotoxic hypoxia. Similarly, hypoxia-induced cell death by cyanide, rotenone, or antimycin A in naive PC12 cells in vitro did not show morphological features of apoptosis but is prevented by BCL-2 and caspase inhibitors (Shimizu et al, 1996). Further, BCL-2 has been shown to inhibit necrotic cell death of GT1-7 cells induced by glutathione depletion or chemical hypoxia (Kane et al, 1993; Myers et al, 1995). The morphologic demise of human $T$ cells caused by staurosporine and CD95 stimulation, two classic apoptotic 


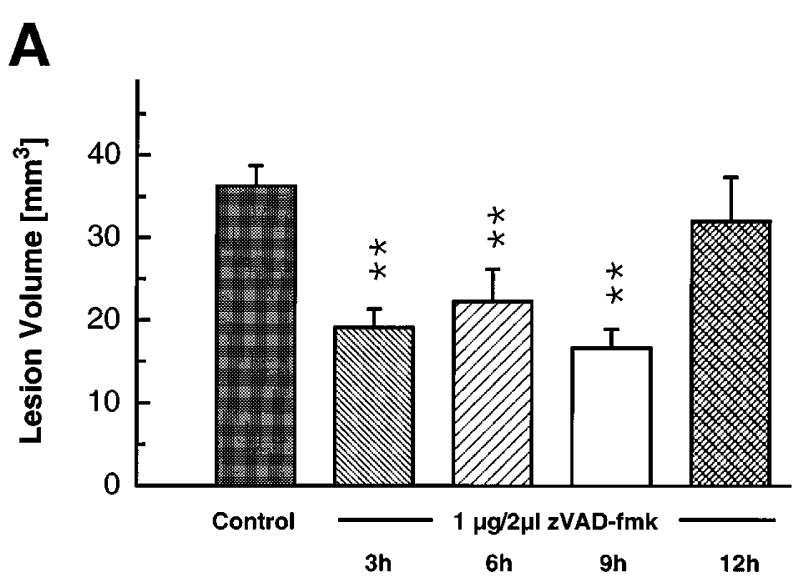

B

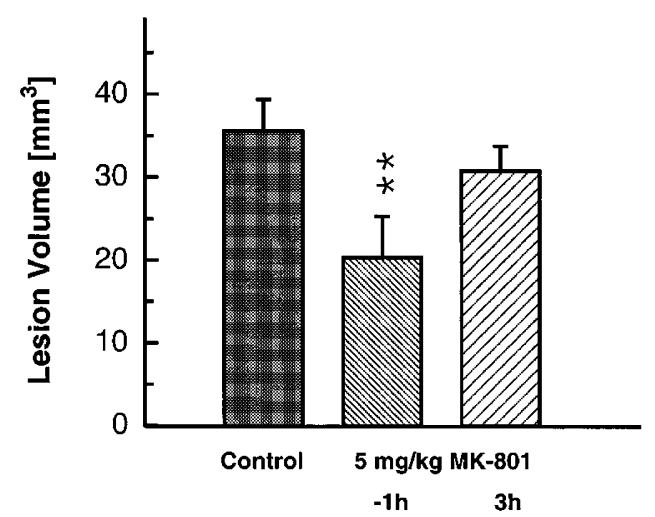

Figure 8 Effects of delayed treatment with zVAD-fmk and MK-801 on lesions produced by malonate. Treatment with (A) zVAD-fmk (1 $\mu \mathrm{g}$ zVAD-fmk dissolved in $2 \mu \mathrm{l}$ of $1 \%$ DMSO intrastriatally) or (B) MK-801 (5 mg/kg i.p.). Controls in $(\mathbf{A})$ received $1 \%$ intrastriatal DMSO injections. Controls in (B) received intraperitoneal saline injections. Lesion volumes were determined 7 days after the malonate lesion (mean \pm S.E.M., $n=7-10,{ }^{\star *} p<0.01$ )

triggers, changes from apoptosis to necrosis when cells are depleted of ATP by treatment with oligomycin. Therefore, the intracellular ATP concentration may be a switch in the morphologic decision between apoptosis and necrosis. Rapid depletion of ATP (Henshaw et al, 1994) after striatal malonate injection may explain the lack of apoptosis. However, interfering with the apoptotic cell death pathway provided protection in this model of energy depletion, even though morphologic evidence of apoptosis may be weak.

Caspases are synthesized as inactive proenzymes which require cleavage at specific aspartate residues to generate active proteases containing a large $(17-20 \mathrm{kDa})$ and a small $(1-12 \mathrm{kDa}$ ) subunit (Cohen, 1997). Here, we report that malonate induces proteolytic activation of NEDD2 (caspase-2), but not caspase-1 and caspase-3. During embryonic development, caspase-2 mRNA is expressed at relatively high levels in various tissues, including brain, liver, kidney and lungs (Kumar et al, 1994). NEDD2 is also expressed in several adult tissues, including post-mitotic

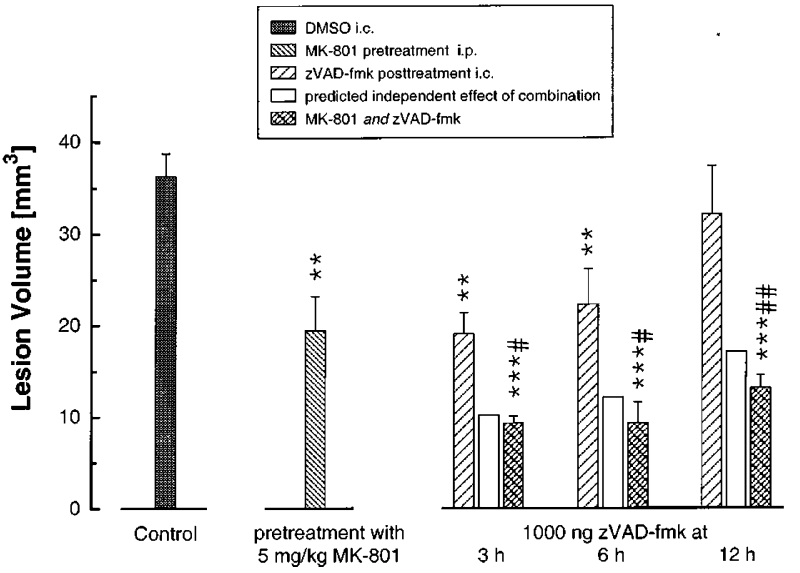

Figure 9 Synergistic effects of a zVAD-fmk and MK-801. Effects of pretreatment with MK-801 (5 mg/kg i.p.) and posttreatment with zVAD-fmk ( $1 \mathrm{~g}$ dissolved in $2 \mu 11 \%$ DMSO intrastriatally) at 3,6 and $12 \mathrm{~h}$, or their combination on striatal malonate lesions. The calculated independent effect (see Materials and Methods) is shown as open bar, the observed effect as hatched bar. Controls were injected $2 \mu \mathrm{l}$ of $1 \%$ DMSO intrastriatally. (mean \pm S.E.M., $n=8-16,{ }^{\star \star} P<0.01,{ }^{\star \star *} P<0.001$ compared with controls, $\# P<0.05$ compared with MK-801 or zVAD-fmk treatment alone, \#\#P<0.001 compared with zVAD-fmk treatment alone, not significant different to MK-801 treatment alone)

neurons (Kumar et al, 1994). Upregulation of caspase-2 mRNA has been observed in response to ischemia-induced cell death in gerbils (Kinoshita et al, 1997). Activation of caspase-2 may require the cleavage of the $51 \mathrm{kDa}$ precursor molecule into subunits of 19 and $12 \mathrm{kDa}$ (Harvey et al, 1997). However, the cleavage site between the prodomain and the larger subunit is not exactly known (Cohen, 1997). Our data indicate, that the size of the larger subunit cleaved may be $24 \mathrm{kDa}$ in rodents. Cleavage of caspase-2 has been reported in other neuronal cell death paradigms, e.g. in the trophic factor withdrawal-induced apoptosis of differentiated PC12 cells (Troy et al, 1997) and staurosporine-induced apoptosis of neuronal GT1-7 cells (Srinivasan et al, 1996).

Using affinity labeling with the biotinylated caspase inhibitor DEVD-CHO we found activation of a $\sim 20 \mathrm{kDa}$ caspase subunit $(\mathrm{p} 20)$ at $12 \mathrm{~h}$ after injection of malonate. p20 recognizes DEVD as a substrate and is likely to correspond to a larger caspase subunit. DEVD is a substrate for active caspase-3-like proteases, including caspase-3, -6, -7, -8, and -10, but not for caspase-2 (Talanian et al, 1997). Here, the p20 fragment was induced later than cleavage of caspase-2 occurs (Figure $3 \mathrm{~A}$ and $4 A)$. Therefore, this protein is unlikely to be identical with the cleaved $\sim 24 \mathrm{kDa}$ fragment of caspase-2. The p20 protein has been considered the cleavage product of full length pro-caspase-3 which is further processed to a p19 and p17 protein (Fernandes-Alnemri et al, 1996). Since we were not able to detect either caspase-3 cleavage with 2 antibodies nor cleavage of the putative substrates PARP and protein kinase $\mathrm{C} \delta$ (data not shown), the p20 fragment may correspond to another activated caspase-3-like caspase. 
A
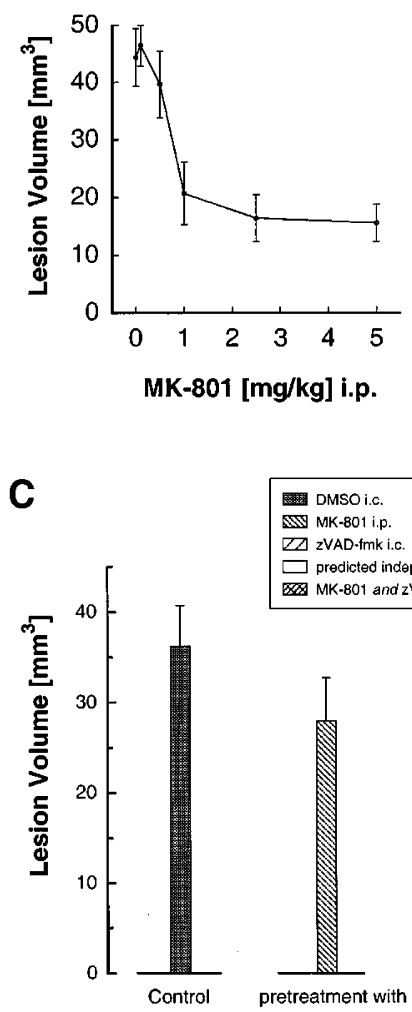
DMSO i.c. MK-801 i.p. $\square$ zVAD.fmk i.c.

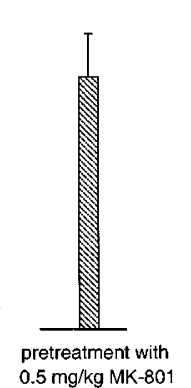
$\square$ predicted independent effect of combination MK-801 and zVAD-fmk

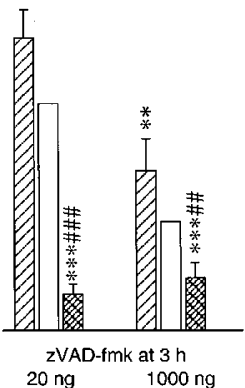

Figure 10 Synergy of subthreshold dosages of MK-801 and zVAD-fmk Effects of MK-801 administered i.p. 30 min prior to and ZVAD-fmk (respective dose dissolved in $2 \mu \mathrm{l} 1 \% \mathrm{DMSO}$ ) intrastriatally injected at $3 \mathrm{~h}$ after striatal malonate lesions. MK-801 (A) and ZVAD-fmk (B) provide dose-dependent protection against lesions induced by $3 \mu \mathrm{mol}$ malonate. The combination of treatment of $0.5 \mathrm{mg} / \mathrm{kg} \mathrm{MK}-801$ with 20 or $1000 \mathrm{ng}$ zVAD-fmk provides synergistic effects (C). The calculated independent effect (see Materials and Methods) is shown as open bar, the observed effect as hatched bar (mean \pm S.E.M., $n=9-10,{ }^{\star \star} P<0.01,{ }^{\star * \star} P<0.001$ compared with controls, $\# \#<0.01$, \#\#\#P<0.001 compared with MK-801 or zVAD-fmk treatment alone)

Activation of a caspase recognizing DEVD is blocked in bcl-2-transgenic mice (Figure $3 \mathrm{~B}$ ). This is the first report to show that BCL-2 blocks the mammalian cell death pathway upstream of caspases in vivo. Malonate-induced activation of caspases occurred in neurons since the increased expression of human BCL-2 in the transgenic mice used is under control of the neuron-specific enolase promotor (Martinou et al, 1994). There is also no evidence for release of $B C L-2$ and uptake by neighboring cells.

zVAD-fmk is a potent, non-specific inhibitor of caspases, but is a poor inhibitor of other cysteine proteases (Armstrong et al, 1996). It has been questioned whether anti-apoptotic therapies that lack neuronal specificity may have unwanted effects on other types of cells, e.g. macrophages or microglia. Ischemia induces expression of caspase-1 in microglia (Bhat et al, 1996). The preferred substrate for caspase- 1 is pro-interleukin- $1 \beta$ that is proteolytically cleaved

to its active form. Blocking the ability of interleukin-1 to bind to its receptor with antibodies or inhibiting its activity have been shown to attenuate ischemic and excitotoxic neuronal damage and edema formation (Relton and Rothwell, 1992; Garcia et al, 1995). Although zVAD-fmk also blocks caspase-1, it is unlikely that this contributed to neuroprotection, since we did not find any increase in binding of the biotinylated caspase-1 specific inhibitor YVAD-CHO to activated caspase-1 for up to $24 \mathrm{~h}$.

A critical issue in the treatment of stroke is the time window for administration of neuroprotective agents. After striatal injections of malonate, the therapeutic window for treatment with lamotrigine and MK-801 was 1 and $2 \mathrm{~h}$, respectively, whereas a free radical spin trap showed efficacy when administered up to $6 \mathrm{~h}$ after malonate injections (Schulz et al, 1995b). zVAD-fmk was effective when administered up to $9 \mathrm{~h}$ after striatal malonate injection. At this time point, NMDA antagonists and glutamate release inhibitors were no longer protective. zVAD-fmk was no longer effective at the time point of $12 \mathrm{~h}$ at which a p20 fragment labeled with DEVD was first detected (Figure 3A).

Malonate toxicity is believed to involve secondary or slow excitotoxicity (Beal et al, 1993; Greene et al, 1993). zVAD-fmk does not block glutamate-induced death in cerebellar granule neurons in vitro at higher glutamate concentrations (Armstrong et al, 1997) and is only marginally effective in protecting against NMDA toxicity in vivo (Hara et al, 1997). Intense excitotoxic insults may produce necrosis in cultured cortical neurons whereas milder excitotoxic insults induce apoptosis (Bonfoco et al, 1995). Glutamate induces early necrosis in a subpopulation of cultured cerebellar granule neurons and delayed apoptosis in neurons surviving the initial death phase (Ankarcrona et al, 1995). These results and the present data suggest that malonate toxicity involves neurons dying by more than one pathway.

The present study suggests, that caspase- 2 may be an important protease in cerebral hypoxia/ischemia. We show that there may be an extended therapeutic window to treat ischemia with caspase inhibitors. Furthermore, a combination of anti-excitotoxic and anti-caspase therapy exerts synergistic effects as well as an even more prolonged therapeutic window. This may provide a novel therapeutic strategy for treatment of stroke.

\section{Material and Methods}

\section{Surgical procedure}

Studies were done in accordance with the European Convention for Animal Care and Use of Laboratory Animals and were approved by the local Animal Care Committee. Male Sprague-Dawley rats weighing $350-375 \mathrm{~g}$ were anesthetized with pentobarbital (50 mg/kg i.p.) and positioned in a David Kopf stereotaxic instrument with the incisor bar set at $3.3 \mathrm{~mm}$ below the interaural line. A $1 \mathrm{~mm}$ burr hole was made in the skull over the left striatum and a $1 \mathrm{~mm}$ guide cannulas affixed with dental acrylic vertically with the tip on top of the brain surface. Malonate (Sigma, St. Louis, MO) was dissolved in 0.1 M PBS and 
zVAD-fmk (Bachem, Heidelberg, Germany) in dimethyl-sulfoxide (DMSO). After recovering for $48 \mathrm{~h}$, injections were made through the guide cannula into the left striatum (coordinates: bregma, $2.6 \mathrm{~mm}$ laterally, $4.5 \mathrm{~mm}$ below dura) in a volume of $1.5 \mu \mathrm{l}$ ( $3 \mu \mathrm{mol}$ malonate) or $2 \mu \mathrm{l}$ (DMSO, zVAD-fmk) using a blunt-tipped 26-gauge Hamilton syringe. All injections were made over $1 \mathrm{~min}$. The needle was left in place for $1 \mathrm{~min}$ before being slowly withdrawn. The advantage of implanting a guide cannula for striatal injections were twofold: (1) Drugs can be exactly injected into the same region at different time points and (2) no anesthesia that might cause neuroprotective hypothermia is needed at the time of striatal injection.

Transgenic mice engineered to express human BCL-2 (Martinou et al, 1994) from the neuron specific enolase (NSE) promoter have been described (Martinou et al, 1994). We bred male founders (strain NSE73A) with the same strain female mice to obtain heterozygous transgenic offsprings, as assessed by PCR analysis of tail DNA. Wild-type littermates were used as controls. Twelve 2-3 month old male mice weighing $20-25 \mathrm{~g}$ in each group were anesthetized with methoxyflurane, and malonate $(0.75 \mu \mathrm{mol}$ in $0.75 \mu \mathrm{l})$ was injected stereotaxically into the striatum. This is equivalent to the dose used in rats that lesions about $2 / 3$ of the striatum. To study the activation of caspases, $0.75 \mu \mathrm{mol}$ of malonate or saline were injected into the striatum of bcl-2-positive mice or wild-type littermates.

\section{Experimental design and treatment groups}

For pharmacological protection studies, 8-12 Sprague-Dawley rats were examined per group. In a first study, $200 \mu \mathrm{g}$ zVAD-fmk dissolved in $2 \mu$ l DMSO or $2 \mu$ l DMSO were injected in the left striatum $30 \mathrm{~min}$ before injection of $3 \mu \mathrm{mol}$ malonate. In a second study, MK-801 (0.5 or $5 \mathrm{mg} / \mathrm{kg}$ ) or saline (vehicle-treated controls) were administered intraperitoneally $30 \mathrm{~min}$ before striatal injection of malonate. $20 \mathrm{ng}, 100 \mathrm{ng}, 500 \mathrm{ng}, 1000 \mathrm{ng}$ or $2000 \mathrm{ng}$ zVAD-fmk dissolved in $2 \mu \mathrm{l}$ of $1 \%$ DMSO or $2 \mu \mathrm{l}$ of $1 \%$ DMSO were injected in the striatum at various time points after striatal injection of malonate. In the awake animals MK- 801 did not reduce body temperature at dosages used.

\section{Quantification of lesion volume}

For pharmacological protection studies rats were killed by decapitation 1 week after striatal malonate injections. The brains were rapidly removed, placed in ice-cold saline for $5 \mathrm{~min}$, and sectioned coronally into slices at $2 \mathrm{~mm}$ intervals. Slices were stained in 2\% 2,3,5-triphenyltetrazolium chloride monohydrate (TTC, Sigma) solution at room temperature in the dark for $30 \mathrm{~min}$ followed by fixation in phosphatebuffered $4 \%$ paraformaldehyde (PFA). The lesioned area (noted by pale staining) was measured on the posterior surface of each section using an image processing system (MCID M4, Imaging Research) by an observer blinded to the experimental conditions. We previously verified the reliability of the TTC measurements in animals injected with malonate on adjacent sections stained with either TTC or Nissl stain (Schulz et al, 1995a). To study the time course of malonate histopathology rats were transcardially perfused with $4 \%$ PFA at 3, 6, $9,12,24 \mathrm{~h}$ and 7 days after striatal malonate injections, paraffinembedded, and $20 \mu \mathrm{m}$ sections at $240 \mu \mathrm{m}$ distance processed for cresyl violet. Four animals at each time point were studied. Bcl-2transgenic mice or littermates were anesthetized and perfused transcardially with $4 \%$ PFA at 7 days after striatal malonate injections, paraffin-embedded, and $20 \mu \mathrm{m}$ sections at $200 \mu \mathrm{m}$ distance processed for cresyl violet. Lesion volumes were measured using an image processing system.

\section{TUNEL staining}

For terminal transferase dUTP nick end-labeling (TUNEL), rats treated with DMSO or ZVAD-fmk 30 min before striatal injection of malonate were deeply anesthetized and perfused with ice-cold $0.9 \%$ saline followed by $4 \%$ PFA. The brains were removed and fixed in $4 \%$ PFA, paraffin-embedded, and $20 \mu \mathrm{m}$ sections processed for TUNEL. The sections were counterstained with cresyl violet for histological evaluation. Quantification of striatal apoptotic neurons was carried out in $350 \mu \mathrm{m}^{2}$-fields centered around the lesion at a magnification of $250 \times$, using an eyepiece graticule. For each animal, counts were made in five sections at $+0.4,+0.2,0,-0.2,-0.4 \mathrm{~mm}$ to bregma. Eight to ten fields per section were averaged. The data were analyzed as the fraction of the total number of neurons detected in the same location in the contralateral unlesioned striatum.

\section{Electron microscopy}

Twenty-four hours after striatal malonate injection, rats were perfused transcardially under deep pentobarbital anesthesia with a fixation solution containing $2 \%$ glutaraldehyde plus $0.8 \%$ PFA solved in $0.05 \mathrm{M}$ cacodylate buffer ( $\mathrm{pH} 7.2,330 \mathrm{mOsm} / \mathrm{l})$. The forebrains were removed and postfixed for $12 \mathrm{~h}$ with the same solution. The specimens were then osmified in an aqueous solution of $1 \% \mathrm{OsO}_{4}$, dehydrated in an alcohol series and embedded into epon. Ultrathin sections (approx. $20 \mathrm{~nm}$ ) were contrasted with $4 \%$ uranyl acetate and $2.6 \%$ lead citrate (both solved in water) and studied with a CM 100 (Philips).

\section{Labeling of activated caspases with biotinylated DEVD-CHO}

Animals were sacrificed after striatal malonate or saline injections at the time points indicated. The striatum was dissected from a $2 \mathrm{~mm}$ thick slice and lysed on ice in $50 \mathrm{mM} \mathrm{Tris} / \mathrm{HCl}, \mathrm{pH} 8$, containing $120 \mathrm{mM} \mathrm{NaCl}, 0.5 \% \mathrm{NP}$ 40, $0.1 \mathrm{mM}$ EDTA, $100 \mu \mathrm{g} / \mathrm{ml} \mathrm{PMSF}, 2 \mu \mathrm{g} / \mathrm{ml}$ aprotinin, $10 \mu \mathrm{g} / \mathrm{ml}$ leupeptin, $50 \mathrm{mM}$ sodium fluoride, and $200 \mu \mathrm{M}$ sodium vanadate followed by centrifugation at $10000 \times g$ for $10 \mathrm{~min}$. We performed reactions in $50 \mu$ l volume containing $2 \mu \mathrm{g}$ of protein per $\mu$ l. Samples were incubated for $25 \mathrm{~min}$ at room temperature with biotinylated DEVD-CHO at $2 \mu \mathrm{M}$. Reactions were stopped by adding an equal volume of denaturating sample buffer. The samples were subjected to SDS-PAGE on $12 \%$ polyacrylamide gels and electroblotted to nitrocellulose membranes for $60 \mathrm{~min}$. After blocking $(1 \mathrm{~h}$ at room temperature), sheets were incubated for $1 \mathrm{~h}$ with streptavidine alkaline phosphatase conjugate $(1: 2500)$. Blotted proteins were visualized by chemiluminescence detection.

\section{Immunoblotting with ICE (caspase-1), Nedd2 (caspase-2), and CPP32 (caspase-3) antibodies}

Mice and rats were sacrificed after striatal malonate or saline injections at the time points indicated. Proteins were extracted as described above. Samples were diluted to $1 \mu \mathrm{g} / \mu \mathrm{l}$ protein and $20 \mu \mathrm{g}$ per lane subjected to SDS-PAGE on $12 \%$ polyacrylamide gels. After electrophoresis and electroblotting to nitrocellulose membranes, the blots were blocked in $250 \mathrm{mM}$ Tris- $\mathrm{HCl}, \mathrm{pH} 8.0,120 \mathrm{mM} \mathrm{NaCl}, 10 \%$ non fat dry milk, $5 \% \mathrm{BSA}, 1 \%$ of serum corresponding to the secondary antibody, $0.5 \%$ Tween 20 and $0.1 \%$ azide for $30 \mathrm{~min}$. The blots were incubated with the first antibody at $4^{\circ} \mathrm{C}$ overnight. The following antisera were used: Caspase-1 p10 (M20) rabbit polyclonal antibody raised against the p10 subunit of murine caspase-1 (Santa Cruz, Heidelberg, Germany), antiserum against a C-terminal peptide of Caspase-2 (Nedd2 p12 C20, Santa Cruz), a monoclonal mouse-anti- 
human Nedd-2 antibody raised against an epitope corresponding to amino acids 225-401 (Transduction Laboratories, Manhead Castle, Exeter, U.K.), an N-terminal rabbit-anti-human anti-CASPASE-3 monoclonal antibody (Upstate, Lake Placid, NY, USA), polyclonal caspase-3 rabbit-anti human $\mathrm{X}$-terminal antibody (kindly provided by Dr. W. Fiers). After three washes in PBS containing 0.05\% Tween 20 , the membranes were incubated with secondary alkaline phosphataseconjugated antibody for $1 \mathrm{~h}$, washed three times in PBS, and stained with $0.2 \mathrm{mg} / \mathrm{ml}$ nitroblue tetrazolium chloride and $0.3 \mathrm{mg} / \mathrm{ml} 5$-bromo4-chloro-3-indolyl-phosphate in $0.1 \mathrm{M}$ Tris $\mathrm{HCl}, \mathrm{pH} 9.5$, containing $50 \mathrm{mM} \mathrm{MgCl}_{2}$ and $100 \mathrm{mM} \mathrm{NaCl}$.

\section{Statistical analysis}

Data are expressed as means \pm S.E.M. values. Tests of variance homogeneity, normality and distribution were performed to ensure that the assumptions required for standard parametric analysis of variance were satisfied. Statistical analysis was performed by ANOVA followed by Fisher's PLSD post hoc test to compare group means. To study whether treatment with MK-801 and zVAD-fmk has synergistic effects, we used the fractional product method (Greco et al, 1995). In the fractional product method, the effect of two independently acting agents is defined as the product of the unaffected fractions after treatment with either drug alone: $f u(1,2)=f u(1) \times f u(2)$. This formula allows to calculate the predicted effect of cotreatment, based on the assumption that two agents do not interact or cooperate in inducing their effects. If the unaffected fraction, that is, the remaining lesion volume, is below the calculated product fu $(1,2)$ after cotreatment, then the two drugs show synergy.

\section{Acknowledgements}

This work was supported by grants from the Deutsche Forschungsgemeinschaft (Schu 932/2-1) and the fortüne program of the University Tübingen. We thank L. Dumitrescu and I. Müller for excellent technical assistance.

\section{References}

Alnemri E, Livingston D, Nicholson D, Salvesen G, Thornberry N, Wong W and Yuan $J$ (1996) Human ICE/CED-3 protease nomenclature. Cell 87: 171

Ankarcrona M, Dypbukt JM, Bonfoco E, Zhivotovsky B, Orrenius S, Lipton SA and Nicotera $P$ (1995) Glutamate-induced neuronal death: a succession of necrosis and apoptosis depending on mitochondrial function. Neuron 15: 961-973

Armstrong RC, Aja T, Xiang JL, Gaur S, Krebs JF, Hoang K, Bai X, Korsmeyer J, Karanewsky DS, Fritz LC and Tomaselli KJ (1996) Fas induced activation of the cell death related protease CPP32 is inhibited by Bcl-2 and by ICE family protease inhibitors. J. Biol. Chem. 271: 16850-16855

Armstrong RC, Aja TJ, Hoang KD, Gaur S, Bai X, Alnemri ES, Litwack G, Karanewsky DS, Fritz LC and Tomaselli KJ (1997) Activation of the CED3/ICE-related protease CPP32 in cerebellar granule neurons undergoing apoptosis but not necrosis. J. Neurosci. 17: 553-562

Beal MF, Brouillet E, Jenkins B, Henshaw R, Rosen B and Hyman BT (1993) Agedependent striatal excitotoxic lesions produced by the endogenous mitochondrial inhibitor malonate. J. Neurochem. 61: 1147-1150

Bhat RT, DiRocco R, Marcy VR, Flood DG, Zhu Y, Dobrzanski P, Siman R, Scott R, Contreras PC and Miller M (1996) Increased expression of IL-1 $\beta$ converting enzyme in hippocampus after ischemia: selective localization in microglia. J. Neurosci. 16: 4146-4154

Bonfoco E, Krainc D, Ankarcrona M, Nicotera P and Lipton SA (1995) Apoptosis and necrosis: two distinct events induced, respectively, by mild and intense insults with $\mathrm{N}$-methyl-D-aspartate or nitric oxide/superoxide in cortical cell cultures. Proc. Natl. Acad. Sci. USA 92: 7162-7166
Campagne M and Gill R (1996) Ultrastructural morphological changes are not characteristic of apoptotic cell death following focal cerebral ischaemia in the rat. Neurosci. Lett. 213: 111-114

Choi DW (1996) Ischemia-induced neuronal apoptosis. Curr. Opin. Neurobiol. 6: $667-672$

Cohen GM (1997) Caspases: the executioners of apoptosis. Biochem. J. 326: 1-16

Fernandes-Alnemri T, Armstrong RC, Krebs J, Srinivasula SM, Wang L, Bullrich F, Fritz LC, Trapani JA, Tomaselli KJ, Litwack G and Alnemri ES (1996) In vitro activation of CPP32 and Mch3 by Mch4, a novel human apoptotic cysteine protease containing two FADD-like domains. Proc. Natl. Acad. Sci. USA 93: $7464-7469$

Friedlander RM, Gagliardini V, Hara H, Fink KB, Li W, MacDonald G, Fishman MC, Greenberg AH, Moskowitz MA and Yuan J (1997) Expression of a dominant negative mutant of interleukin- $1 \beta$ converting enzyme in transgenic mice prevents neuronal cell death induced by trophic factor withdrawal and ischemic brain injury. J. Exp. Med. 185: 933-940

Garcia JH, Liu K-F and Relton JK (1995) Interleukin-1 receptor antagonist decreases the number of necrotic neurons in rats with middle cerebral artery occlusion. Am. J. Pathol. 147: 1477-1486

Greco RW, Bravo G and Parsons JC (1995) The search for synergy: a critical review from a response surface perspective. Pharmacol. Rev. 47: 331-385

Greene JG, Porter RHP, Eller RV and Greenamyre JT (1993) Inhibition of succinate dehydrogenase by malonic acid produces an excitotoxic lesion in rat striatum. J. Neurochem. 61: 1151-1154

Hara H, Friedlander RM, Gagliardini V, Ayata C, Fink K, Huang Z, Shimizu-Sasamata M, Yuan J and Moskowitz MA (1997) Inhibition of interleukin $1 \beta$ converting enzyme family proteases reduces ischemic and excitotoxic neuronal damage. Proc. Natl. Acad. Sci. USA 94: 2007-2012

Harvey NL, Butt AJ and Kumar S (1997) Functional activation of Nedd2//CH-1 (Caspase-2) is an early process in apoptosis. J. Biol. Chem. 272: 13134-13139

Henshaw R, Jenkins BG, Schulz JB, Ferrante RJ, Kowall NW, Rosen BR and Beal MF (1994) Malonate produces striatal lesions by indirect NMDA receptor activation. Brain Res. 647: 161-166

Kane DJ, Sarafian TA, Anton R, Hahn H, Butler Gralla E, Selverstone Valentine J, Örd T and Bredesen DE (1993) Bcl-2 inhibition of neuronal death: decreased generation of reactive oxygen species. Science 262: 1274-1277

Kinoshita M, Tomimoto H, Kinoshita A, Kumar S and Noda M (1997) Up-regulation of the Nedd2 Gene encoding an ICE/CED-3-like cysteine protease in the gerbil brain after transient global ischemia. J. Cereb. Blood Flow Metab. 17: 507-514

Krajewska M, Wang H-G, Krajewski S, Zapata JM, Shabaik A, Gascoyne Rand Reed JC (1997) Immunohistochemical analysis of in vivo patterns of expression of CPP32 (Caspase-3), a cell death protease. Cancer Res. 57: 1605-1613

Kuida K, Zheng TS, Na SQ, Kuan CY, Yang D, Karasuyama H, Rakic P and Flavell RA (1996) Decreased apoptosis in the brain and premature lethality in CPP32 deficient mice. Nature 384: $368-372$

Kumar S, Kinoshita M, Noda M, Copeland NG and Jenkins NA (1994) Induction of apoptosis by the mouse Nedd2 gene, which encodes a protein similar to the product of the Caenorhabditis eleganscell death gene ced-3and the mammalian IL-1 $\beta$-converting enzyme. Genes Dev. 8: 1613-1626

Li P, Allen H, Banerjee S, Franklin S, Herzog L, Johnston C, McDowell J, Paskind M, Rodman L, Salfeld J, Towne E, Tracey D, Wardwell S, Wei F-Y, Wong W, Kamen $\mathrm{R}$ and Seshardi T (1995a) Mice deficient in IL-1 $\beta$-converting enzyme are defective in production of mature IL- $1 \beta$ and resistant to endotoxic shock. Cell 80 : $401-414$

Li Y, Sharov VG, Jiang N, Yao F, Zaloga C, Sabbah HN and Chopp M (1995b) Ultrastructural and light microscopic evidence of apoptosis after middle cerebral artery occlusion in rat. Am. J. Pathol. 146: 1045-1051

Martinou J-C, Dubois-Dauphin M, Staple JK, Rodriguez I, Frankowski H, Missotten M, Albertini P, Talabot D, Catsicas S, Pietra C and Huarte J (1994) Overexpression of BCL-2 in transgenic mice protects neurons from naturally occuring cell death and experimental ischemia. Neuron 13: 1017-1030

Myers KM, Fiskum G, Liu Y, Simmens SJ, Bredesen DE and Murphy AN (1995) Bcl-2 protects neural cells from cyanide/aglycemia-induced lipid oxidation, mitochondrial injury, and loss of viability. J. Neurochem. 65: 2432-2440

Relton JK and Rothwell NJ (1992) Interleukin-1 receptor antagonists inhibit ischaemic and excitotoxic neuronal damage in the rat. Brain Res. Bull. 29: 243246 
Schulz JB, Henshaw DR, Siwek D, Jenkins BG, Ferrante RJ, Cipolloni PB, Kowall NW, Rosen BR and Beal MF (1995a) Involvement of free radicals in excitotoxicity in vivo. J. Neurochem. 64: 2239-2247

Schulz JB, Matthews RT, Jenkins BG, Brar P and Beal MF (1995b) Improved therapeutic window for treatment of histotoxic hypoxia with a free radical spin trap. J. Cereb. Blood Flow Metab. 15: 948-952

Schulz JB, Matthews RT, Jenkins BG, Ferrante RJ, Siwek D, Henshaw DR, Cipolloni PB, Mecocci P, Kowall NW, Rosen BRandBeal MF (1995c) Blockade of neuronal nitric oxide synthase protects against excitotoxicity in vivo. J. Neurosci. 15: 8419-8429

Schulz JB, Bremen D, Reed JC, Lommatzsch J, Takayama S, Wüllner U, Löschmann PA, Klockgether T and Weller M (1997) Cooperative interception of neuronal apoptosis by BCL-2 and BAG-1 expression: Prevention of caspase activation and reduced production of reactive oxygen species. J. Neurochem. 69: 20752086
Shimizu S, Eguchi Y, Kamiike W, Waguri S, Uchiyama Y, Matsuda H and Tsujimoto Y (1996) Retardation of chemical hypoxia-induced necrotic cell death by Bcl-2 and ICE inhibitors: possible involvement of common mediators in apoptotic and necrotic signal transduction. Oncogene 12: 2045-2050

Srinivasan A, Foster LM, Testa M-P, Örd T, Keane RW, Bredesen DE and Kayalar C (1996) Bcl-2 expression in neural cells blocks activation of ICE/CED-3 family proteases during apoptosis. J. Neurosci. 16: $5654-5660$

Talanian RV, Quinlan C, Trautz S, Hackett MC, Mankovich JA, Banach D, Ghayur T, Brady KD and Wong WW (1997) Substrate specificities of caspase family proteases. J. Biol. Chem. 272: $9677-9682$

Troy CM, Stefanis L, Greene LA and Shelanski ML (1997) Nedd2 is required for apoptosis after trophic factor withdrawal, but not superoxide dismutase (SOD1) downregulation, in sympathetic neurons and PC12 cells. J. Neurosci. 17: 1911 1918 